\title{
Ética e Arquitetura: a responsabilidade de uma novíssima crítica em Portugal ${ }^{1}$
}

\section{Ethics and Architecture: the responsibility of a brand new critique in Portugal}

DOI: $10.46814 / \operatorname{lajdv3n5-025}$

Recebimento dos originais: 01/05/2021

Aceitação para publicação: 31/06/2021

\author{
Tiago Lopes Dias \\ Ph.D. \\ Universidade do Porto, Faculdade de Arquitetura \\ Via Panorâmica s/n, 4150-564 Porto, Portugal \\ Tdias@ arq.up.pt
}

\begin{abstract}
O argumento do presente texto defende que o "Novo Brutalismo", sendo indiscutivelmente um debate arquitetónico de origem britânica, era movido por um princípio universal: a adesão intelectual aos problemas do seu tempo. A luta contra o academicismo e o historicismo, a aceitação da realidade e das diferentes formas de cada cultura construir o seu habitat, e a crescente importância atribuída aos utilizadores da arquitetura, constituem pontos essenciais para a revisão dos modelos arquitetónicos levada a cabo no pós-guerra. Estes princípios despertam o interesse de uma nova geração de arquitetos portugueses cada vez mais crítica e atenta ao debate internacional, que os assimila por coincidência de interesses, mais do que por conexão ou influência direta. A metodologia adotada passa por recuperar alguns argumentos dos textos de 1955 e de 1966 do crítico Reyner Banham, o principal ideólogo do Novo Brutalismo, com particular incidência nas propostas dos arquitetos Alison e Peter Smithson e o seu papel no grupo Team 10. Após se introduzirem as origens e o contexto do debate, esboça-se o panorama da situação portuguesa nesses anos, com especial incidência na difusão da "novíssima" geração de arquitetos (sensivelmente, os nascidos entre finais de 1920 e inícios de 1930) por iniciativa da revista Arquitectura. Finalmente, apresentam-se os argumentos de dois representantes dessa geração - Nuno Portas e Pedro Vieira de Almeida - cuja relação com o brutalismo não reside em questões estéticas, de forma ou de tratamento das superfícies, mas sim em questões éticas, ou seja, de compromisso com a "utilidade social da arquitetura". Num primeiro momento, expõe-se um debate em torno à habitação coletiva centrado em métodos e posições críticas, que se complementa num segundo momento com uma breve abordagem a uma obra de arquitetura na qual ambos têm responsabilidade.
\end{abstract}

Palavras chave: arquitetura; brutalismo; 1960s; crítica; ética;

\begin{abstract}
The argument of the present text argues that the "New Brutalism", being arguably an architectural debate of British origin, was driven by a universal principle: the intellectual adherence to the problems of its time. The struggle against academicism and historicism, the acceptance of reality and the different ways each culture builds its habitat, and the growing importance given to the users of architecture, are essential points for the post-war revision of architectural models. These principles have awakened the interest of a new generation of Portuguese architects that is increasingly critical and attentive to the international debate, assimilating them through coincidence of interests, rather than through direct

\footnotetext{
${ }^{1}$ Versão revista da comunicação apresentada, com o mesmo título, no X Seminário DoCoMoMo Brasil (“Arquitetura moderna e internacional: conexões brutalistas, 1955-75”, realizado em Curitiba em Outubro de 2013) e incluida nos anais do congresso.
} 
connection or influence. The methodology adopted involves recovering some arguments from the 1955 and 1966 texts of the critic Reyner Banham, the main ideologue of New Brutalism, with particular focus on the proposals of the architects Alison and Peter Smithson and their role in the Team 10 group. After introducing the origins and context of the debate, the panorama of the Portuguese situation in those years is outlined, with special focus on the diffusion of the "brand new" generation of architects (roughly those born between the late 1920s and early 1930s) through the initiative of the magazine Arquitectura. Finally, we present the arguments of two representatives of this generation -Nuno Portas and Pedro Vieira de Almeida- whose relationship with brutalism does not lie in aesthetic questions, of form or surface treatment, but in ethical questions, i.e., their commitment to the "social utility of architecture. In a first moment, a debate around collective housing centered on methods and critical positions is exposed, which is complemented in a second moment with a brief approach to a work of architecture in which both have responsibility.

Keywords: architecture; brutalism; 1960s; criticism; ethics;

\section{INTRODUÇÃO}

Nas primeiras linhas do artigo "The New Brutalism”, Reyner Banham assinala a autoridade que os historiadores de arquitetura tinham adquirido em anos recentes e a sua influência nos métodos de pensamento, de crítica e de ensino que prevaleciam no meio arquitetónico britânico. Na sua opinião, o Novo Brutalismo - expressão utilizada dois anos antes por Peter Smithson na descrição de um projeto para uma casa no Soho de Londres, e desde então em circulação pelas revistas da especialidade ${ }^{2}$ — só podia ser entendido dentro do contexto de um gradual processo de historização da arquitetura moderna.

Em opinião de Banham, a contribuição mais importante para a disciplina da parte de um historiador, depois de Nikolaus Pevsner, foi o livro de Rudolf Wittkower Architectural Principles in the Age of Humanism (1949). Resultado de anos de investigação no Warburg Institut de Londres, onde leccionou, o livro transformara-se numa referência incontornável para historiadores e arquitetos ${ }^{3}$. Uma das manifestações mais evidentes da sua influência foi a interpretação levada a cabo pelos chamados Neo-Palladianos, empenhados na recuperação formal da arquitetura do Cinquecento através de exercícios de estilo rotineiros e académicos. A influência foi visível também em arquitetos jovens como Alison e Peter Smithson, cujos primeiros projetos se estruturavam a partir de composições geométricas axiais de grande clareza formal, utilizando noções de proporção e simetria que demonstram o conhecimento dos estudos de Wittkower.

\footnotetext{
1 Alison Smithson; Peter Smithson. "House in Soho". Architectural Design, Dezembro 1953. A designação "New Brutalism" aparece posteriormente numa pequena nota na Architectural Review (n ${ }^{\circ} 688$, Abril de 1954) e num editorial da Architectural Design de Janeiro de 1955, ambos não assinados.

${ }^{3}$ Veja-se, por exemplo, a influência exercida em Colin Rowe, de quem Wittkower foi orientador no Warburg Institut: "The Mathematics of the Ideal Villa" foi escrito em 1947.
} 
Banham argumenta que o Novo Brutalismo surge como uma reação à crescente academização das artes que se refletia, no caso da arquitetura, em dois movimentos esteticamente opostos: o racionalismo do Estilo Internacional e o historicismo dos Neo-Palladianos. No caso dos Smithson, deteta essa reação nas propostas para os concursos do conjunto habitacional de Golden Lane, em Londres (1952), e da Universidade de Sheffield (1953), que vê como uma superação da fase marcada pelos concursos para a Escola de Hunstanton (ganho em 1949) e para a Catedral de Coventry (1951). De Golden Lane, Banham destaca «a determinação em construir imagens visuais coerentes através de meios não formais, enfatizando a circulação visível, a identificação de cada uma das células de habitação e validando a presença dos seres humanos como parte integrante do todo» ${ }^{4}$. Da ampliação da Universidade de Sheffield, considera que vai ainda mais longe, ao explorar um «sentido intuitivo de topologia» que permite superar a composição elementar da régua e do esquadro.

A Escola de Hunstanton (1949-54) era, segundo Banham, a primeira obra do Novo Brutalismo, mas a evolução patente nos concursos de 1952 e 1953 levou-o a relativizar a importância da sua principal característica, a «legibilidade formal de todo o conjunto». Aos outros dois princípios que ainda julgava relevantes para a caracterização do movimento, a «exposição legível da estrutura» e a «valorização dos materiais empregues em bruto, as found», acrescentava uma noção mais experiencial (memorability as an image), sugerindo que o Novo Brutalismo se aproximava da grande arquitetura de Le Corbusier e da sua vontade de «établir rapports émouvants» ${ }^{5}$. No entanto, deixa claro que o Novo Brutalismo é arquitetura do seu tempo, e não do tempo de Le Corbusier, e que, embora seja um ato de rebeldia de jovens arquitetos, apresenta um vigoroso compromisso com a atualidade do pós-guerra, o que por si só é meritório.

Passados onze anos, Reyner Banham reúne num volume consideravelmente extenso argumentos do Novo Brutalismo que procurava recuperar e re-enquadrar no seu contexto histórico. $\mathrm{O}$ livro, que se assume como um ensaio crítico, repete o título do artigo de 1955, sendo contudo acrescentado um subtítulo em forma de interrogação que funciona como guia de leitura: «Ético ou Estético?». Duas questões essenciais são abordadas: a primeira retoma a ligação dos Smithson com um grupo de arquitetos, artistas, historiadores e críticos de arte que se reunia no Institute of Contemporary Arts (ICA) de Londres para organizar atividades à margem da programação oficial ${ }^{6}$; a segunda é a relação entre as ideias brutalistas e o colapso dos Congrès Internationaux d'Architecture Moderne

\footnotetext{
${ }^{4}$ Reyner Banham. “The New Brutalism”. Architectural Review 688, Dezembro 1955, 355-361.

${ }^{5} \mathrm{O}$ artigo é precedido de uma citação de Le Corbusier retirado do livro de 1923 "Vers une Architecture": "L'Architecture c'est, avec des matières bruts, établir des rapports émouvants”.

${ }^{6}$ Reyner Banham pertencia ao mesmo círculo intelectual dos Smithsons no ICA, tendo assumido o papel de dinamizador e organizador do Independent Group, assim conhecido devido à sua vontade de se distanciar de todo e qualquer caráter institucional.
} 
(CIAM), instigado pelo Team 10, no qual o casal britânico teve uma ação preponderante. Estas ideias ocupam os capítulos centrais do livro e surgem antes de Banham falar de um «estilo brutalista» ${ }^{7}$.

Sobre a primeira questão, Banham sublinha a grande coerência de pensamento que unia a atividade dos Smithson em torno do ICA com as propostas arquitectónicas que desenvolviam nos mesmos anos, sendo ambas marcadas por uma semelhante visão antiacadémica e antiestética.-Quanto à participação e aos contactos estabelecidos pelos Smithson nos CIAM, é incisivo ao considerar como uma das contribuições mais importantes para o Novo Brutalismo a apresentação do conjunto residencial em Casablanca, do ateliê ATBAT, na revista Architectural Design (Fig.1). O texto dos Smithson, que incluía uma “declaração de princípios” na primeira página, assumia a cumplicidade com a obra apresentada por Georges Candilis no CIAM IX (Aix-en-Provence, 1953), ao verificarem estar ambos a desenvolver um tema comum: a «extensão da habitação» ${ }^{8}$. Banham procura demonstrar como, nas breves linhas escritas para contextualizar a obra, se desenvolve uma nova forma de pensamento onde as preocupações brutalistas vão muito além da mera questão plástica de materiais expostos e de superfícies sem tratamento. Este "manifesto", sintetizado numa frase citada no editorial que precedia o texto — «entendemos a arquitetura como o resultado direto de uma forma de vida»——, está assente em dois princípios fundamentais: a necessidade de um estudo aprofundado sobre a forma como as pessoas realmente vivem (sugerida em Casablanca na disposição do pátio como peça central da casa, de acordo com a tradição cultural islâmica); e o reconhecimento de que o conceito de habitat era indissociável de uma margem de liberdade de adaptação a que todo o homem deveria aspirar. Ao destacar estes pontos, Banham procura demonstrar que a ética social tinha por então um peso nas preocupações dos Smithson que relegava para segundo plano a materialização da arquitetura.

Esta obra, apreciada pelos Smithson como a maior conquista arquitectónica desde a Unité d'Habitation de Marselha de Le Corbusier, poderá ter estado na origem de algumas reflexões sobre o habitat escritas pelo casal entre 1953 e $1954^{10}$, que por sua vez serviram de base aos documentos preparatórios do CIAM X. Nos encontros levados a cabo a partir de 1954, de Doorn a La Sarraz ${ }^{11}$,

\footnotetext{
${ }^{7}$ Reyner Banham. The New Brutalism. Ethic or Aesthetic? Stuttgart and Bern: Karl Kramer Publisher, 1966. Após relembrar as duas referências máximas do Novo Brutalismo (a Unité de Marselha de Le Corbusier e o Instituto de Tecnologia de Chicago de Mies van der Rohe) no capítulo 2, e a obra fundadora (a Escola de Hunstanton) no capítulo 3, refere ainda o Centro de Arte de Yale de Louis Khan no capítulo 4. O ponto "The Brutalist Style" é antecedido pelas Casas Jaoul de Le Corbusier e os apartamentos em Ham Common de James Stirling.

${ }^{8}$ Alison Smithson; Peter Smithson. "Collective Housing in Morocco". Architectural Design, Janeiro 1955: 2.

${ }^{9}$ A frase é dos Smithson, e está incluída, entre outras, no editorial de Theo Crosby que antecede o citado texto. Cf. Architectural Design, Janeiro 1955: 1.

${ }^{10}$ Dois documentos intitulados "Habitat". In: Smithson, Alison, ed. The Emergence of Team 10 out of C.I.A.M.: Documents. London: Architectural Association, 1982,13-16.

${ }^{11}$ Doorn, cidade na Holanda onde se reuniram, entre 29 e 31 de Janeiro de 1954, van Ginkel, van Eyck, Bakema, Hovens Greve, Voelcker e os Smithsons. La Sarraz foi o local da reunião do conselho CIAM e TEAM 10 entre 7 e 11 Setembro de 1955.
} 
Alison e Peter Smithson fazem prevalecer uma nova forma de pensar o urbanismo desenvolvida a partir de comunidades com diferentes graus de complexidade e escalas de associação, funcionando cada uma como um "todo dentro de um todo", com lógicas de crescimento específicas que deviam ter em conta todo o meio físico e cultural envolvente. Este conceito de urbanismo, que os próprios chamavam «ecológico» ${ }^{12}$, iria ser assimilado por todo o grupo oficialmente encarregue de organizar o CIAM X: o Team 10.

A ação dos Smithson será decisiva para pôr fim a alguns dogmas do CIAM, sobretudo o esquematismo funcionalista da Carta de Atenas, e Banham sustém que as ideias brutalistas estão em direta relação com a sua proposta de uma aproximação mais humana e pragmática aos problemas do urbanismo e do habitat. Se cada problema do urbanismo era uma forma única de associação humana, num particular tempo e num particular lugar, não havia soluções "ideais" nem definitivas; a "solução ideal" era sempre pensada partindo da realidade crua, em bruto, de determinado contexto de intervenção. Por outro lado, ao reivindicarem o abandono dos modelos analíticos a favor de um estudo das comunidades tal como existem e se influenciam mutuamente (e não como ideias abstratas) estavam a assumir um compromisso de envolvimento direto oposto ao idealismo utópico da Ville Radieuse.

\section{PORTUGAL E A NOVÍSSIMA GERAÇÃO}

Até meados dos anos 1950, Portugal é um país essencialmente agrícola, com uma indústria incipiente e incapaz de produzir alterações significativas no tecido social. Contudo, coincidindo com o plano de recuperação económica dos Estados Unidos da América para a Europa, esta situação alterase, pese embora a sua aceitação renitente e tardia devido à política de neutralidade definida pelo regime autoritário do Estado Novo em relação à Segunda Guerra Mundial. O rápido processo de industrialização levado a cabo a partir desta década tem um impacto assinalável nos núcleos urbanos litorais, onde se instalam as principais indústrias. Sobretudo em Lisboa, torna-se evidente a dificuldade da cidade em absorver o êxodo rural e fornecer alojamento condigno às populações que fugiam da miséria.

No panorama arquitectónico, e após um breve período em que o próprio regime "apadrinha" algumas conquistas do Movimento Moderno em edifícios com presença urbana significativa ${ }^{13}$, os modelos internacionais são adotados com hesitação, quer porque os valores que veiculam não interessam ao regime, quer por insegurança ou debilidade teórica dos projetistas. Contudo, durante os

\footnotetext{
12 V. documento intitulado "Draft framework 4. CIAM X. Instructions to Groups", não assinado e não datado, possivelmente de finais de 1954). In: The Emergence of Team 10..., Op.Cit., 38.

${ }^{13}$ Tomem-se como exemplo o Instituto Superior Técnico (1927-35), as Gares Marítimas de Alcântara (1934-43) ou a Igreja de Nossa Senhora de Fátima (1934-38), obras de Porfírio Pardal Monteiro (1897-1957) em Lisboa.
} 
anos cinquenta, algumas contribuições de Le Corbusier, atualizadas pela plasticidade brasileira (na originalidade dos seus quebra-luzes e pára-sóis), serão aplicadas em programas de habitação coletiva que propõem uma escala mais adequada para resolver as necessidades que se verificam, embora surjam inevitavelmente desfasados de um debate internacional já empenhado na revisão crítica desses mesmos modelos.

Por outro lado, em 1955 inicia-se o Inquérito à Arquitetura Regional Portuguesa, coordenado pelo Sindicato Nacional de Arquitectos, um trabalho de campo feito por seis equipas que percorrem, a pé ou de motociclo, todo o território continental, observando as formas de organização e de construção vernáculas, populares ou anónimas ${ }^{14}$. Uma feliz coincidência permitirá aplicar alguns princípios estudados no Inquérito à proposta apresentada pela delegação portuguesa no CIAM X (Dubrovnik, 1956): um plano para uma comunidade rural no nordeste transmontano com cerca de 40 habitações. Coincidência, pois se o âmbito do Inquérito era maioritariamente o território rural, a sua forma de organização característica (a aldeia) era apenas uma das quatro "escalas de associação" — entre a construção isolada, a cidade e a metrópole ${ }^{15}$ — que o Team 10 tinha proposto serem estudadas para o problema do habitat. No conhecido esquema das escalas de associação, a metrópole ocupava o lugar central, pelo seu grau de máxima complexidade e por ser a que necessitava respostas urgentes.

A nível académico, preparava-se a reforma que daria lugar à transformação do ensino artístico em ensino superior, mas as Escolas de Belas-Artes, sobretudo a de Lisboa, continuavam dominadas por um academismo completamente desfasado da realidade, onde predominavam os exercícios de "grande composição" e os estereótipos Beaux-Arts. A quem desejava acabar o curso com um exercício menos convencional do que o "projeto como se fosse para construir", não lhe restava senão rumar ao Porto, onde Carlos Ramos vinha promovendo, desde 1952, outras abordagens ao ensino da arquitetura, beneficiando do ambiente mais familiar e da distância ao centro do poder. Dentro do pequeno grupo de estudantes que, por então, optaram por apresentar provas teóricas como Concurso para a Obtenção do Diploma em Arquitectura, estão Nuno Portas e Pedro Vieira de Almeida ${ }^{16}$.

Neste complexo contexto, marcado pela falta de coesão profissional e de tradição crítica e teórica (cada vez mais necessária para se poder destrinçar as diversas tendências arquitetónicas e interpretá-las a outro nível que não o do mero "exercício de estilo", fosse ele Beaux-Arts, regionalista

\footnotetext{
14 Publicado em formato de livro, em 1961, pelo Sindicato Nacional dos Arquitectos, como Arquitectura Popular em Portugal.

15 "Isolate or homestead", "village", "town”, "city". Referências que os Smithson consideravam simbólicas para uma série muito mais complexa de relações que podiam ser expressadas como "grande grupo", "grupo", "pequeno grupo", etc.

16 "A habitação social: proposta para a metodologia da sua arquitectura" e "Ensaio sobre o espaço da arquitectura" foram as teses apresentadas por Nuno Portas e Pedro Vieira de Almeida no Porto, respetivamente em 1959 e 1963.
} 
ou Estilo Internacional), caberá a Nuno Portas lançar os mais vigorosos apelos à classe profissional para se alcançar um programa de objetivos comuns:

\begin{abstract}
Tomar a realidade como instância da génese arquitectónica era para nós um princípio pressentido como essencial, mas perigoso, visto os desequilíbrios e tanta imobilidade com que vivemos. De fato, o momento local condiciona a linguagem mas não poderemos mais deixar que esgote o seu significado, pois isso equivaleria a retirar-lhe qualquer alcance renovador, a desistir de reinventar os organismos e estruturas construídas em que se processam as existências; a aceitar reduzir o conceito de arquitetura a uma técnica do gosto, a embelezadora de paisagens. Processo inaceitável, pois cada vez mais pensamos que interessa mais atingir, embora imperfeitamente, o que é estruturalmente importante, que chegar a um alto nível de virtuosismo, bom gosto ou elegância no que nos interessa menos. ${ }^{17}$
\end{abstract}

Antes de esclarecermos em que contexto Nuno Portas escreve este "pequeno manifesto" com ecos brutalistas, devemos considerar um texto anterior, publicado em 1959 na revista Arquitectura, a cargo de uma nova equipa editorial empenhada na revisão dos modelos do CIAM. Nas primeiras linhas, Portas (por então um dos seus membros mais ativos) considera ser urgente rever «o conceito de 'modernidade'», agora que as conquistas formais do Movimento Moderno eram uma realidade na paisagem urbana de Lisboa e começavam a ser socialmente aceites. O debate que propunha, e que visava também romper com alguns dogmas, desenvolvia-se a partir das contribuições de uma geração recém-chegada à profissão ${ }^{18}$. Entre um conjunto de obras recentes, que a revista divulgará nos seguintes números, Portas encontra um denominador comum nas seguintes características: a vontade de aproximação à realidade geográfica e humana do contexto de intervenção; a utilização livre e inteligente das técnicas e dos materiais disponíveis; e uma certa disponibilidade para aceitar as contingências do projeto. Assim, apela à "novíssima geração" para participar de forma corajosa no debate, assumir posição e esclarecer objetivos por forma a ser possível estruturar e conferir «um certo grau de síntese e de eficácia operativa» a um conjunto de atuações dispersas, para que daí possa resultar uma metodologia válida.

Dos "novíssimos" apresentados no seguimento deste texto, é dado um destaque particular a Álvaro Siza. Nuno Portas, que analisa as suas primeiras obras, apercebe-se de estar perante um dilema: se, por um lado, o autor encaixava na estratégia da "novíssima geração" (por exemplo, ao «abdicar de vocabulários feitos quando possam ser estes fatores de abstração formal» ${ }^{19}$ ), por outro lado, os seus trabalhos revelavam-se tentadores «no plano do gosto», pelo inquestionável virtuosismo que demonstravam na execução global e, sobretudo, na pormenorização algo exagerada. ${ }^{20}$ Não

\footnotetext{
${ }^{17}$ Nuno Portas. A arquitectura para hoje. Lisboa, Livros do Horizonte,1964, 19 (2ª ed.: 2008).

${ }^{18}$ Nuno Portas. "A responsabilidade de uma novíssima geração no Movimento Moderno em Portugal". Arquitectura 66, Dezembro 1959, 13-14.

19 lbid.

${ }^{20}$ Portas. “3 obras de Álvaro Siza Vieira”. Arquitectura 68, Julho de 1960, 13-32.
} 
conseguindo evitar algumas observações sobre os valores plásticos das obras (as texturas do betão, da alvenaria ou do reboco; a utilização de madeira nos caixilhos ou na estrutura da cobertura, por vezes exposta) o jovem crítico consegue encontrar o rumo que lhe convém ao deixar claro a sua preferência por uma das obras, o Centro Paroquial de Matosinhos (1956-59) (Fig.2).

A organização dos principais espaços de uso público em torno a um pátio, promovendo a interação, o encontro e a experiência comunitária, levam-no a considerar que «não é um efeito plástico, um partido estrutural ou sequer um gosto formal que comanda a obra, como é vulgar na rotina profissional (...), mas uma interpretação da vida coletiva materializada palpavelmente no espaço, ordenadora de toda a obra». A exemplaridade de Siza está aqui sugerida: no saber incorporar outras motivações para a arquitetura, «procuradas noutros níveis que são os da realidade vital dos homens». Este princípio base, não muito distante do entendimento da arquitetura "como o resultado direto de uma forma de vida" (Smithson), é o que lhe parece ser objetivável a ponto de poder constituir uma «plataforma conceptual e um método comum» para as atuais gerações ${ }^{21}$.

\section{ARQUITETURA PARA HOJE}

Em 1964, com motivo do concurso aberto para um lugar de professor na Escola Superior de Belas-Artes de Lisboa, Nuno Portas tem oportunidade de reunir um conjunto de preocupações teóricas para as quais vinha chamando a atenção, de forma sistemática embora dispersa, num livro. Resultante do programa apresentado, o livro (ao qual pertence a citação acima destacada) sintetizava no título uma declaração de princípios e retomava uma das questões essenciais lançadas no texto de 1959 da “novíssima geração”. Em A arquitectura para hoje (Fig.3), escrevia:

[A] formação do espaço responderá a uma procura minuciosa das necessidades humanas, resolvendo no plano da forma as ambiguidades e contradições das exigências pessoais e sociais —não de uma pessoa ou classe teóricas ou futuras, mas (...) tomadas na sua existência concreta, nos seus impasses e contradições - como tem vindo a ser pressentido pelas ciências humanas. ${ }^{22}$

O mote académico serviu a Portas para argumentar que a crise que se vivia no ensino mais não era que o reflexo de uma crise maior: a da «inserção do arquiteto numa sociedade industrial e de consumo de massa» ${ }^{23}$. Depois de observar a perda de relevância em que a disciplina corria o risco de cair, apresenta no segundo capítulo um conjunto de novas responsabilidades passíveis de estruturar, enquanto base metodológica, o trabalho do arquiteto. Entre elas, a aproximação aos utentes da arquitetura através da contribuição das ciências sociais e humanas.

\footnotetext{
${ }^{21}$ Ibid.

${ }^{22}$ Portas. "A responsabilidade...", 14.

${ }^{23}$ Portas. A arquitectura para hoje. Op.cit., 125.
} 
Portas contava já com uma experiência levada a cabo no Laboratório Nacional de Engenharia Civil (LNEC), onde estava integrado na Divisão de Construção e Habitação desde 1963, nomeadamente na elaboração de um inquérito às populações urbanas sobre as suas necessidades em matéria de habitação, com o apoio de um sociólogo para a fase de inquirição ${ }^{24}$ e de uma equipa multidisciplinar para a análise sistemática de dados (Fig.4). Este trabalho previa recolher o feedback dos utentes sobre o meio onde habitavam, por forma a integrar essa informação no processo de desenho e eliminar tanto quanto possível tomadas de decisão arbitrárias. O propósito de estudar as necessidades reais das populações para as quais se constrói coincide com o objetivo dos Smithson de "estudar as comunidades tal como existem". Por outro lado, este inquérito experimental introduziu outra questão fundamental: partilhava, com o trabalho conduzido pelo Sindicato Nacional dos Arquitetos em 195556, a obrigação ética de aproximação à realidade local, mas deslocava o objeto de estudo do âmbito rural para o âmbito urbano. As comunidades relativamente estáveis e homogéneas que participavam na sedimentação de técnicas e tradições ao longo dos anos não existiam nos novos bairros urbanos, construídos de raiz em periferias metropolitanas para famílias de estratos sociais e proveniências diversas.

Em A arquitectura para hoje, Portas recolhe duas objeções frequentemente colocadas ao método de observação direta dos inquéritos: a primeira, que tal metodologia era contraditória com a «natureza fundamentalmente repetitiva» de um programa que teria de ser "massificado" se quisesse dar resposta ao problema que enfrentava; a segunda, que os novos bairros, uma vez construídos, conformavam novas formas de organização social que os inquéritos não teriam capacidade de antecipar. À primeira, responde invocando uma exigência deontológica: os «erros de conceção devido a ideias feitas, aos subjetivismos mais ou menos românticos e às deformações ideológicas mais ou menos totalitárias» teriam agora consequências sobre milhares de famílias, repercutindo-se em $\operatorname{cadeia}^{25}$. Quanto à segunda objeção, sublinha que se devem distinguir as "necessidades-imperativas", que tendiam a sofrer uma crescente homogeneização no quadro de uma sociedade de massas, das "necessidades-aspiração", que apenas se podiam pressentir na fase de inquirição e se referiam a fatores característicos de sociedades urbanas como a mobilidade social ${ }^{26}$.

Esta metodologia de investigação distanciava-se significativamente da estratégia do Movimento Moderno, que preferia simplificar alguns dados do problema para lhe contrapor uma

\footnotetext{
${ }^{24}$ Adérito de Sedas Nunes, considerado o fundador da sociologia moderna em Portugal, acompanhou os trabalhos de elaboração, condução e escolha da amostra do inquérito e participou também na redação do relatório "Inquérito-piloto sobre necessidades familiares em matéria de habitação" (Lisboa, LNEC).

${ }^{25}$ Portas. A arquitectura para hoje. Op.cit., 45.

${ }^{26}$ Seguindo neste ponto o pensamento do sociólogo Paul-Henry Chombart de Lauwe, cujos livros Famille et Habitation (I \& II) foram de referência para Nuno Portas.
} 
solução clara e rotunda. Portas afirmava não ser «rendosa, nesta matéria, a pretensão de simplificar», deixando claro que os inputs das ciências sociais e humanas deviam ajudar a analisar as necessidades em toda a sua complexidade, contribuindo para uma maturação arquitetónica que, até agora, se «alimentava [exclusivamente] da participação pessoal do autor na vida íntima e nos ambientes em que se moviam os utentes» ${ }^{27}$.

No seguimento das considerações sobre a investigação dirigida à utilização do espaço e à satisfação das necessidades a ele ligadas, Portas refere o «momento de mútua incompreensão» entre José Antonio Coderch e Georges Candilis no encontro do Team 10 em Royaumont (1962), quando o primeiro respondeu ao segundo — a propósito da apresentação do projeto de Toulouse-le-Mirail— que necessitava seis meses para desenhar uma moradia unifamiliar. Não obstante o fascínio que sentia pela obra do arquiteto catalão, e de certamente subscrever que "não são génios o que precisamos agora", Portas deixa claro que "trabalhar com uma corda atada ao pé para não se afastar dos homens que melhor conhece" 28 é algo que o arquiteto não se pode dar ao luxo de fazer, pois a sua responsabilidade, numa sociedade de massas, é dar resposta ao problema "do maior número", tal como enunciado por Candilis. Se, por um lado, admite que o método individualista de Coderch «não pode aguentar a complexidade e a extensão de uma vasta estrutura», por outro sublinha que as massas trabalhadoras da nova Toulouse de Candilis não têm por que ser menos perscrutadas do que o cliente individual de Coderch, já não por conhecimento direto, mas sim através de modelos estudados anteriormente por sociólogos e antropólogos «que procuram conhecê-las no âmago das suas aspirações, no que as une (homogeneíza) como no que as distingue (tipifica)» ${ }^{29}$.

Esta consideração de Nuno Portas parecia responder ao apelo feito por quem pressentiu a necessidade de uma posição intermédia entre Coderch e Candilis ou, em palavras de quem assistiu ao debate, de «uma nova síntese entre os números 1 e $25.000 »{ }^{30}$. As ciências sociais lidavam exatamente com esse processo que Fernando Távora via como paradoxal, no qual à medida que se conhecem melhor o homem e os fenómenos sociais tudo se vai revelando mais complexo. O próprio admitia que não parecia ser então possível chegar a «conclusões claras, lúcidas, esquematizadas» como o foi quando se reuniram os homens da Carta de Atenas, e Portas insistia em que «a 'experimentação da vida real' é um trabalho que não autoriza (...) pedido de receitas a curto prazo».

\footnotetext{
${ }^{27}$ Portas. A arquitectura para hoje. Op.cit., 47.

${ }^{28}$ Cito livremente o artigo de Coderch "No son génios lo que necesitamos ahora", publicado originalmente em 1961 na revista Domus. Portas não refere diretamente este texto, embora por aquela altura já tivesse sido publicado em Portugal (Arquitectura 73, Dezembro de 1961).

${ }^{29}$ Portas. A arquitectura para hoje. Op.cit., 48.

${ }^{30}$ Fernando Távora. “O Encontro de Royaumont”. Arquitectura 79, Julho 1963, 1.
} 
O entusiasmo de Portas pela contribuição das ciências sociais não o impede de lançar alguns alertas sobre o trabalho dos inquéritos, nomeadamente, quanto à burocratização e inutilidade dos números e dos gráficos quando não relacionados operacionalmente com o projeto; sobre o estado incipiente dos estudos sociais no país; ou sobre o perigo de se transformarem em álibi para adiar decisões estratégicas que podiam ser tomadas a outros níveis ${ }^{31}$. Este último ponto parece ser importante, tendo em conta que uma das contribuições mais relevantes para este debate foi a de Pedro Vieira de Almeida, que considerava que uma das decisões estratégicas que perdia relevância, entre dados relativos a superfícies, conforto térmico e sonoro, índices de utilização e circulação, etc., era a do próprio arquiteto: «a arquitetura limita-se assim a herdar um esquema 'funcional' predeterminado por várias contribuições, e no fundo mais não faz do que revestir um esqueleto de exigências precisamente definidas» ${ }^{32}$.

Vieira de Almeida defende que a responsabilidade social da arquitetura tem de partir da sua própria essência crítica, ou seja, da «modulação de espaços praticáveis». Deviam ser diretamente enunciadas, ao nível do espaço da arquitectura, propostas de experiências socialmente relevantes, se a disciplina não quisesse voltar ao «arranjo de fachada contra a qual se revoltou o Movimento Moderno» ${ }^{33}$. Mas ao contrário do que sucedeu então, onde a investigação foi no sentido de destinar a cada porção de espaço um uso (pre)determinado, agora sentia que era possível —e até necessáriorevalorizar os espaços de indecisão, "não-saturados" de uso e de forma, já que considerava que a interpretação de um programa não era apenas ordenação e hierarquização funcional, mas «interpretação em termos de espaço» ${ }^{34}$. Tendo em conta os excessos dos anos 1920-30, alertava para um sentido de economia que tendia a tornar-se desatualizado, para uma racionalização que não era integralmente controlada, e para uma debilitação da capacidade de saber viver espaços de uso indeterminado, com a nefasta «perda do sentido de uma liberdade e uma democracia intrínsecas, vitais» ${ }^{35}$.

A revalorização crítica do espaço de uso indeterminado —o "espaço-perdido" — será feita em quatro artigos publicados num jornal cultural, onde para além do enunciado da questão, estuda a sua utilização em três casos: habitação, edifícios escolares e religiosos. O primeiro era o mais delicado, por

\footnotetext{
${ }^{31}$ Portas. A arquitectura para hoje. Op.cit., 57. Referidos em nota-de-rodapé.

${ }^{32}$ Pedro Vieira de Almeida. "Da utilidade social da arquitectura". Análise Social 6, 1964, 240-241.

${ }^{33}$ Ibid.,241.

${ }^{34}$ Ao afirmar que a leitura de um programa é também um problema crítico, traduzido na dialética «funções-espaço», Vieira de Almeida aproximava-se da posição de Nuno Portas, que tinha feito uma crítica ao artigo "Da utilidade social da arquitectura", afirmando que «é crescentemente impossível separar programa de conceção», sendo que no «plano de programação e definição especializada se responde e propõem novas formulações espaciais das necessidades». Cf. $A$ arquitectura para hoje, 44, 54.

${ }^{35}$ Pedro Vieira de Almeida. “O Espaço-perdido. Proposta para a sua revalorização crítica”. Jornal de Letras e Artes, 27 de Janeiro 1965.
} 
ser o programa mais sujeito a pressões económicas (traduzidas em redução de áreas) mas também o mais urgente, por ser no âmbito privado onde a apropriação ganha o seu pleno sentido. Observando a tendência dos anos do pós-guerra de destinar a uma divisão (normalmente em proximidade dos quartos ou da sala) um uso mais indefinido ou livre, Vieira de Almeida considera que a maleabilidade de utilização deveria ser pensada para «animar o espírito de toda a casa», e não para ficar confinada a um único compartimento. Assim, a experiência inglesa do all-purpose room, de certa forma re-interpretada no espaço exterior de Golden Lane (Fig.5), parecia-lhe insuficiente enquanto elemento fomentador de uma «atitude ativa de habitar» ${ }^{36}$.

Para tal, propunha que outros espaços — corredores, vestíbulos, pátios ou varandas - fossem incluidos, para que toda a casa se pudesse constituir como uma "estrutura aberta", no sentido que Nuno Portas lhe deu: o de um «processo de formação e transformação no tempo» ou «de sobrevivência funcional ${ }^{37}$. Como referência, dava o exemplo das torres de habitação colectiva no bairro de Olivais Norte (1957-68) de Nuno Teotónio Pereira, António Pinto de Freitas e Nuno Portas (Fig.6). Na articulação entre a sala e a varanda dos fogos de maior área parecia-lhe claro «haver várias sugestões de possibilidades de habitar, permitindo portanto uma adequação à maneira individual de entender a casa sem renunciar a uma malha de sentido pedagógico», acrescentando: «são feitas propostas de habitar mas não determinações» ${ }^{38}$. Desta forma, entendia ser possível evitar que a única margem de liberdade dos utentes fosse a função a dar à "divisão extra" (que, uma vez definida, se cristaliza em longos períodos de tempo).

A concepção estrutural do "espaço-perdido" em programas rigidamente controlados viria a ser corroborada no trabalho de apuramento ao inquérito-piloto do LNEC, publicado em 1967. Como sublinhou Nuno Portas, mesmo tendo em conta as limitações da amostragem, era evidente a necessidade de uma flexibilidade na utilização, o que o levava a afirmar que «a casa deve ser um terreno de apropriação muito menos prescritivo do que aquele a que se está habituado», e também a observar que nem os projetos fechados (de dependências convencionais) nem as opções onde «tudo comunica» pareciam fornecer respostas válidas, a nível arquitetónico, para «toda a ambiguidade e diversidade dos comportamentos reais» e para a imprevisível evolução das necessidades humanas ${ }^{39}$.

\footnotetext{
${ }^{36}$ Pedro Vieira de Almeida. "O Espaço-perdido. Proposta para a sua revalorização crítica. III-Habitação”. Jornal de Letras e Artes, 26 de Maio 1965.

${ }^{37}$ Portas. A arquitectura para hoje, 80-81.

${ }^{38}$ Almeida. "O Espaço-perdido... III-Habitação", 9.

${ }^{39}$ Nuno Portas. "Desenho e apropriação do espaço da habitação". Arquitectura 103, Maio/Junho 1968, 124-128. Este texto constitui uma síntese do relatório de apuramento ao inquérito-piloto. Cf. Portas; Valente Pereira. "Inquérito-piloto sobre necessidades familiares em matéria de habitação II", LNEC, 1967.
} 


\section{UMA «AVENTURA EM BETÃO» OU UMA OFERTA À CIDADANIA?}

Ao longo dos anos 1960, o interesse pelas questões formais e plásticas vai dando passagem, progressivamente, a preocupações éticas e sociais, o que se deve sem dúvida à crispação do ambiente político, com Portugal a acompanhar, neste aspeto, o resto do mundo ocidental. No caso de Nuno Portas e de Pedro Vieira de Almeida, trata-se, mais do que uma mudança de interesses, de uma confirmação das primeiras hipóteses lançadas nas suas teses académicas. Sintomática da forma como o debate arquitetónico foi orientado a partir de certa altura é a receção crítica a uma obra seminal dos anos 1960, a Igreja do Sagrado Coração de Jesus (1962-76).

A propósito das primeiras obras de Álvaro Siza, definiu Nuno Portas a arquitetura brutalista como «aquela onde a ideia que a organiza fica tão eficaz e nuamente expressa que é gritada ou imposta ao entendimento, ao comportamento dos seus utilizadores», aquela «pensada como proposta ecológica rudemente técnica exprimindo diretamente os valores do grupo humano ${ }^{40}$. Pedro Vieira de Almeida fez questão de matizar esta afirmação, ao observar que a qualidade espacial das primeiras obras de Siza era prejudicada pela força da proposta sintática. No Centro Paroquial, por exemplo, considerava que havia uma «saturação por proposta de vida», no sentido em que o espaço parecia impor um comportamento uniforme e prescritivo, sem fornecer qualquer sinal que solicitasse uma colaboração ativa dos utentes, e por isso sem qualquer "abertura" para a sua apropriação ${ }^{41}$. O reparo sobre a falta de um grau justo de ambiguidade espacial que promovesse a liberdade de utilização alude a uma postura ética, postura que Reyner Banham considerava fundamental e que designou como ethic of permissiveness, e que Vieira de Almeida faria questão de assinalar como característica da Igreja do Sagrado Coração.

Elaborada por Nuno Teotónio Pereira em co-autoria com Nuno Portas, com o apoio de uma vasta equipa que integrava alguns dos melhores arquitetos daquela geração (incluindo Vieira de Almeida), a igreja insere-se num lote de quarteirão pequeno em solução de continuidade, deixando porém que a vida de rua flua naturalmente pelo espaço interior do quarteirão, através da ligação do acentuado desnível entre as duas ruas marginais (Fig.7). Em 1970, aquando da inauguração da primeira fase da obra com parte dos seus equipamentos por concluir (passados oito anos após o concurso público, ganho em 1962), Vieira de Almeida escreve dois artigos num jornal generalista, após algumas imagens da igreja circularem como publicidade ao construtor ou como ilustração de despesismo

\footnotetext{
${ }^{40}$ Nuno Portas. "Casa de Chá da Boa Nova (Álvaro Siza Vieira)”. Arquitectura 88, Junho 1965, 98.

${ }^{41}$ Pedro Vieira de Almeida. "Uma Análise da Obra de Siza Vieira”. Arquitectura 96, Março/Abril 1967, 64-67. A primeira obra de plena maturidade é, na perspectiva do autor, a Piscina das Marés em Leça da Palmeira.
} 
público $^{42}$. Analisa então de forma didática a que considera ser a sua maior qualidade: o abrir-se a uma apropriação por parte do público ${ }^{43}$. Considerando o longo tempo entre a concepção e a abertura, e aceitando que a linguagem formal é «necessariamente datada» — estrutura em betão aparente, painéis exteriores de betão feitos in situ, blocos de cimento no revestimento de paredes-, faz questão de sublinhar que a obra saiu deste difícil teste «valorizada com sentidos novos de leitura das suas possibilidades». Essas possibilidades, acentuadas pelo estado inacabado da obra, têm a ver com um «espírito que não é o de simples utilizar, mas verdadeiramente apropriar de, tomar posse»; espírito que considera ter sido incorporado no processo projetual, sobretudo numa das suas linhas mestras: a proposta de um conjunto grande e variado de adros, articulados a diferentes níveis através de uma escadaria, e o efeito destes espaços exteriores na gradação da intimidade e na preparação «do ato de entrar» ${ }^{44}$.

O significado do episódio algo caricatural que descreve de um dos dias inaugurais —a curiosidade de um transeunte em saber «se ali sempre se vai dar cinema à malta»—é recuperado num artigo que publicará mais tarde na revista Arquitectura: ao observar que o espaço destinado a Centro Paroquial continua incompleto e se organizam reuniões informais nos patins das escadas, sugere que outro programa lhe seja destinado, para que não se destrua a animação que reina por ali então ${ }^{45}$ (Fig.8). Assumindo que os programas de equipamento urbano são as melhores oportunidades para pedagogicamente se propor o uso de um espaço liberto de prescrições, e tendo em conta que a Igreja Católica dava por então sinais de atualização ${ }^{46}$ mas a sociedade portuguesa era ainda muito conservadora, expressa o seu receio de que uma vez terminado o Centro Paroquial, aquela agitação vital «acabe por ser enquadrada, classificada, arrumada em salas para tal fim mortífera e irremediavelmente prontas e demasiado adequadas». «A uma Igreja que arquitetonicamente se abre para a cidade», conclui, «parece legítimo propor que a cidade se introduza no seu interior» ${ }^{47}$.

Nuno Portas, que já tinha mencionado, em A arquitectura para hoje, a renovação radical do conceito de igreja — de casa de Deus para casa da comunidade_- corrobora a leitura crítica de Pedro Vieira de Almeida, ao admitir que a protagonista da Igreja do Sagrado Coração era a «rua-escadório» desenhada simultaneamente como elemento distributivo e espaço de estar, público e exterior, embora

\footnotetext{
${ }^{42}$ V. página de publicidade da construtora Engil intitulada "Uma aventura em betão" (Diário de Lisboa, 19-6-1970) e uma notícia sobre o elevado custo da obra: "Poderemos ficar com a consciência tranquila?" (Diário de Lisboa, 26-6-1970).

${ }^{43}$ Pedro Vieira de Almeida. "Igreja do Sagrado Coração”. Jornal A Capital, Suplemento Literatura \& Arte, 22 e 29 de Julho 1970.

${ }^{44}$ Almeida. "Igreja do Sagrado Coração". Jornal A Capital, Suplemento Literatura \& Arte, 22 de Julho 1970 , p.1.

45 Pedro Vieira de Almeida. "Duas Igrejas: Sagrado Coração de Jesus e Paroquial de Almada". Arquitectura 123, Setembro/Outubro 1971,163-164.

${ }^{46}$ Refiro-me ao Concílio Vaticano II, iniciado em 1962.

${ }^{47}$ Almeida. "Duas Igrejas: Sagrado Coração...", 164.
} 
com um carácter "interiorizado" pelas proporções e o tratamento das superfícies envolventes (Fig.9). Com esta opção, esperavam «que aquele conjunto [pudesse] descrever uma pequena história de mudanças nas formas de apropriação e uso pelos seus habitantes, paroquianos e passantes» e que «estimulasse o inventar coisas a fazer nele passando de sacro a profano e de profano a 'novos sacros' $\rangle^{48}$. Quanto à linguagem, recordava apenas que a grande quantidade de técnicos que tinham passado pela obra levara a uma inevitável acumulação de marcas pessoais, o que espelhava afinal um processo natural de ir fazendo cidade.

\section{5 ÉTICA E ESTÉTICA}

Em 1957, quando a delegação inglesa se dissolveu oficialmente e assinou um documento propondo que a estrutura dos CIAM seguisse o mesmo caminho, a discussão sobre o Novo Brutalismo continuava em algumas revistas britânicas. Os Smithson observaram que, até então, os argumentos eram de ordem estilística, quando a sua essência era ética. A luta que empreenderam no seio do Team 10 surgiu como reação aos movimentos britânicos do Neo-Palladianismo, do Picturesque e da CidadeJardim, e também aos princípios dos CIAM sintetizados na Carta de Atenas. Com a mesma ambição, embora não com os mesmos meios, a geração portuguesa dos "novíssimos" empreendeu a sua batalha contra outros movimentos ou tendências que conviviam em ecléticos exercícios de estilo (Beaux-Arts, regionalista, "Português Suave", etc.) mas também, ou sobretudo, contra o caráter rotineiro e burocrático que foi adquirindo alguma arquitetura moderna. A sua investida é dirigida contra a "grande narrativa" moderna e a degradação semântica da linguagem do Estilo Internacional, que se verifica à medida que as premissas morais e sociais do Movimento Moderno vão ficando esquecidas. Também para os "novíssimos", os argumentos eram de ordem ética.

Se o Novo Brutalismo, enquanto rótulo, nunca encontrou expressão significativa em Portugal (em parte, também devido à ambiguidade que lhe subjaz ${ }^{49}$ ), os seus princípios foram absorvidos numa cumplicidade silenciosa por quem compartia o dever ético de atender à realidade, às necessidades de cada contexto e de cada população, com todas as suas contradições e confusões — como defendiam os Smithson no texto "Cluster city"-, não para construir um "radioso mundo novo", mas sim para estruturar com urgência uma "arquitectura para hoje". Portas e Vieira de Almeida sabem que o papel

\footnotetext{
${ }^{48}$ Portas. "Igreja do Sagrado Coração de Jesus: testemunho de um dos autores". Arquitectura 123, Setembro/Outubro $1971,171$.

49 Observando a natureza da expressão, Banham não tem dúvidas quanto ao seu caráter evasivo. Desde logo, porque na origem do seu batismo se confundiam a vontade de classificar, de aplicar um rótulo descritivo própria do trabalho dos críticos, e a vontade de provocar, de lançar uma boutade, própria da vanguarda que se rebela contra alguma instituição. Por outro lado, a sua semelhança com outros ismos divulgados nas revistas como trouvaille do pós-guerra ("O Novo Empirismo" ou "O Novo Humanismo") era, no mínimo, irónica.
} 
do arquiteto já não é o do grande pedagogo que antecipa necessidades e modos de vida "futuros"; mas sabem igualmente que ele não pode fugir à responsabilidade de estruturar espaços onde cada homem possa desenvolver livremente a sua forma de habitar. Seja através de um método inter-disciplinar (os inquéritos de base sociológica), seja através de mecanismos próprios da disciplina (o espaço da arquitectura), ambos colocam a presença humana e seu comportamento dentro dos edifícios em primeiro plano, em detrimento da composição formal dos mesmos, algo já apreciado por Banham no texto "The New Brutalism".

Como exemplo paradigmático de uma obra de arquitectura que assimila o(s) debate(s) coetâneo(s), a Igreja do Sagrado Coração, sem prescindir de uma linguagem "do seu tempo" (reconhecível como brutalista), responde a uma série de novas exigências éticas, nomeadamente: uma arquitetura que já não tem como objetivo a perfeição, que se quer menos pura e objetual, mais processual e "contaminada" pela vida quotidiana, aberta à cidade e à apropriação da cidadania, dando sentido ao que Vieira de Almeida descreveu como o «sentido aleatório do estar e do viver». A somar a estas questões, a igreja parece oferecer também uma resposta à questão que Banham colocou como subtítulo do seu livro de 1966. O crítico britânico percebeu, por então, que a força plástica de obras como a Galeria de Arte de Yale, de Louis Kahn, e as Casas Jaoul, de Le Corbusier, impediram que o Novo Brutalismo se desenvolvesse numa determinada direção; se as suas premissas permaneceriam vinculadas a princípios éticos, o seu reconhecimento internacional passaria também pela estética. A conciliação de uma "ética" com uma "estética" é uma das principais lições da Igreja do Sagrado Coração, uma obra que absorveu o espírito do seu tempo e, contudo, permanece intemporal.

\section{RECONHECIMENTOS}

O trabalho de investigação pós-doutoral do autor tem lugar no Centro de Estudos de Arquitetura e Urbanismo da Faculdade de Arquitetura da Universidade do Porto (CEAU-FAUP), e é financiado pela Fundação para a Ciência e a Tecnologia de Portugal, através do programa de Estímulo ao Emprego Científico (CEEC individual, 2017). 


\section{REFERÊNCIAS BIBLIOGRÁFICAS}

ALMEIDA, Pedro Vieira de. Da Utilidade Social da Arquitectura. Análise Social 6: 237-248. Lisboa, 1964.

-. O Espaço-perdido. Proposta para a sua revalorização crítica (I-IV). Jornal de Letras e Artes. Lisboa, 27/1, 17/2, 26/5 e 4/8 de 1965.

—. Uma análise da obra de Siza Vieira. Arquitectura 96: 64-67. Lisboa, Março/Abril 1967.

—. Igreja do Sagrado Coração (I \& II). A Capital, Suplemento Literatura \& Arte. Lisboa: 22 e 29/7 1970.

—. Duas Igrejas: Sagrado Coração de Jesus e Paroquial de Almada. Arquitectura 123: 163-164. Lisboa, Setembro/Outubro 1971.

BANHAM, Reyner. The New Brutalism. Architectural Review 688: 355-361.London, 1955.

—. The New Brutalism. Ethic or Aesthetic? Suttgart and Bern: Karl Kramer Publisher, 1966.

LOPES DIAS, Tiago. Teoria e desenho da arquitectura em Portugal: Nuno Portas e Pedro Vieira de Almeida, 1957-1974. Tese de Doutoramento, Universidade Politécnica da Catalunha, 2017.

PORTAS, Nuno. A responsabilidade de uma novíssima geração no Movimento Moderno em Portugal. Arquitectura 66: 13-14. Lisboa: Dezembro 1959.

—. 3 Obras de Álvaro Siza Vieira. Arquitectura 68: 13-32. Lisboa, Julho 1960.

-; Gomes, Ruy José. Inquérito Piloto sobre as necessidades familiares em matéria de habitação. Lisboa: Laboratório Nacional de Engenharia Civil, 1963.

—. A arquitectura para hoje. Lisboa: Livros Horizonte, 1964.

—. Casa de Chá da Boa Nova (Álvaro Siza Vieira). Arquitectura 88: 97-103. Lisboa, Junho 1965.

—. Desenho e apropriação do espaço da habitação. Arquitectura 103: 124-128. Lisboa, Maio/Junho 1968.

—. Igreja do Sagrado Coração de Jesus: testemunho de um dos autores. Arquitectura 123: 171-172.

SMITHSON, Alison and Peter. Collective Housing in Morocco. Architectural Design: 2-7. London, January 1955.

—. An Alternative to the Garden-City Idea. Architectural Design: 229-231. London, July 1956.

—. Cluster City. Architectural Review 730, 333-336. London, 1957.

SMITHSON, Alison (ed.). The Emergence of Team 10 out of C.I.A.M.: Documents. London: Architectural Association, 1982.

TÁVORA, Fernando. O Encontro de Royaumont. Arquitectura 79: 1. Lisboa, Julho 1963. 